\title{
VALORIZAÇÃO DE BAIRROS ANTIGOS E RESSIGNIFICAÇÃO DA ALTERIDADE: O EXEMPLO DE WAZEMMES EM LILLE
}

Tradução de Sylvanie Rivasseau

Uma parte das mudanças vividas pelas grandes metrópoles nas últimas décadas se deve ao seu papel econômico, sua valorização estética e seu crescimento populacional, especialmente quando antigos bairros populares começam a ser procurados por diferentes classes sociais e vêm a conhecer o que se designa por gentrificação (Bassand, Kaufmann \& Joye, 2007). A gentrificação dos bairros envolve um processo de redefinição dos espaços urbanos: as classes médias se tornam mais presentes em detrimento das classes populares, enquanto os equipamentos industriais e comerciais saem de cena para dar entrada a outros estabelecimentos e serviços. É isso que vem ocorrendo, desde a década de 1960, em certos bairros próximos aos centros de diversas capitais e grandes metrópoles. Evidentemente, nem todos os espaços em questão conhecem esse processo de maneira idêntica. Hoje em dia, são valorizados tanto pelos discursos políticos quanto por investimentos práticos e diversos trabalhos para transformar seu aspecto físico. A fim de se tornarem os belos bairros das cidades - dos quais estão muitas vezes próximos eles tendem a ser descritos como lugares de harmoniosos cruzamentos sociais e culturais. Da maneira como são descritos pelos seus promotores, esses espaços encarnam a diversidade social, esta que é tão pouco definida, assim como pesquisada, desde os anos 1970 na França. Ainda segundo o ponto de vista dos promotores, esses bairros representam uma conquista no domínio da interculturalidade, conhecida como interpenetração de civilizações 
conforme definido por Bastide (2000), noção utilizada mais recentemente com a meta de integrar diversas populações que habitam a França e que não compartilham dos mesmos traços culturais. Nesse contexto, o encontro com o Outro parece menos assustador e até mesmo, em alguns aspectos, atraente ou ainda sinônimo de exotismo a domicílio.

É esta a redefinição da alteridade que queremos questionar, nos apoiando em uma pesquisa ainda em andamento. Na interseção de uma antropologia urbana e de uma sociologia da ação pública, nos embasamos na perspectiva desenvolvida por Max Weber e seu conceito de confraternização ${ }^{1}$ (Weber, 1982), bem como a de Ulf Hannerz (1983) e sua concepção das redes sociais para questionar os fundamentos dos meios que conectam os cidadãos. Este artigo visa abordar a dinâmica urbana em bairros submetidos à gentrificação, e mais precisamente aquela de Wazemmes, bairro perto do centro da cidade de Lille, no Norte da França, que tem experimentado mudanças sensíveis nas últimas décadas. ${ }^{2}$ Este bairro, hoje apresentado como um espaço cosmopolita, onde a "diversidade" convive bem, conta com uma ação pública em diversos domínios, sobretudo no registro social e cultural. Considerado um lugar emblemático no aspecto da urbanidade e etnicidade, que, nas últimas décadas, tem se beneficiado de uma reversão apreciativa - de um espaço difamado em razão da delinquência e do medo por causa da forte presença de imigrantes, é agora valorizado como um lugar de interculturalidade. Segundo a perspectiva daqueles que defendem a "coesão social" 3 ou os que vivem nestas situações, a diversidade se refere, principalmente, a supostas diferenças em relação a culturas denominadas de origem. Mas, quando a população tende a refletir a heterogeneidade social, a diversidade inclui na sua definição, segundo os mesmos locutores, a diferença de posicionamento social. Esta mudança de contexto, há que se deixar claro, provavelmente condiciona a relação com a alteridade e busca justificar intervenções ou modificações envolvendo o processo de redefinir a apreciação e a utilização do bairro, bem como para conservar as posições das pessoas em relação a esta transformação. Espera-se, deste modo, contribuir para a compreensão dos processos pelos quais um local associado a espaço "sensível" torna-se, ou tende a tornar-se um lugar valorizado. A perspectiva adotada não é aquela de Richard Florida (2002), ${ }^{5}$ que evoca as cidades criativas, com um arranjo de contribuições conjuntas de um coletivo de atores (artistas, população etc.), mas compreender o uso político e social da cultura enquanto suporte para um embelezamento da cidade, onde a ação pública se dá com a finalidade de melhorar a convivência conjunta. ${ }^{6} \mathrm{~A}$ abordagem aqui é concebida como uma extensão do trabalho iniciado por Ruth Glass (1963), que primeiro fala de gentrificação para designar um processo de povoamento em que as classes médias e altas se estabelecem em bairros próximos ao centro da cidade, enquanto os antigos habitantes de classes populares deixam esses locais (Authier \& Bidou-Zacha- 
rias, 2008). Para esclarecer a história recente de Wazemmes, vamos primeiro analisar o que pode ser chamado de um embelezamento enquanto processo discursivo, morfológico e cultural análogo à gentrificação, antes de ver se em tal contexto é alterada a vivência da alteridade. Vamos ver como o bairro se transforma fisicamente e, sobretudo, como se multiplicam as iniciativas culturais. Debruçar-nos-emos, de forma menos aprofundada, na análise das relações de alteridade que geram tal contexto. Faremos isto a partir de observações, bem como a partir de entrevistas concebidas para averiguar as trajetórias das pessoas, visando refletir sobre a construção social, administração pública e eventual reapreciação da alteridade. Esta última questão será abordada através de sua construção social, a história dos indivíduos segundo uma análise social das diferentes fases de suas vidas e suas relevâncias para a vida prática do bairro. Ao dizer construção social, destacamos dois processos: o de socialização do indivíduo, pelo qual ele aprende a definir o estrangeiro, ${ }^{7}$ e o de publicização, pelo qual as diferenças (religiosas, culturais, sociais) ganham visibilidade por debates públicos. Por administração pública, insis timos na aplicação prática dessa aprendizagem e na adaptação que acompanha as situações em que a pessoa participa. Sobre Wazemmes, sem ignorar as lógicas privadas do meio imobiliário - que pesam muito, apesar de não serem abordadas aqui -, o questionamento se limita às mudanças recentes impulsionadas por poderes públicos e os eventuais efeitos sociais provenientes do cruzamento em espaço físico público do bairro em contexto de gentrificação. A questão que queremos esclarecer, na medida em que o estado de desenvolvimento da pesquisa o permita, é a dos eventuais efeitos do embelezamento sobre a definição prática da alteridade.

\section{EMBELEZAR PARA TORNAR SEGURO OS ESPAÇOS URBANOS?}

A cidade de Lille passou por mudanças significativas nos âmbitos econômico e cultural nos últimos anos. Capital econômica, desde a Revolução Industrial, de uma região voltada para a indústria têxtil, metalúrgica e as minas de carvão, a cidade sofreu um declínio entre as décadas de 1960 e 1980. Então, a partir da década de 1990, ela viu se afirmar uma conversão para o setor terciário, com diversas realizações marcantes. Primeiramente, o surgimento de um novo bairro de negócios, Euralille, construído em 1988. A chegada do trem de alta velocidade $\left(\mathrm{TAV}^{8}\right)$ no bairro em 1993, obtido através de múltiplas intervenções de Pierre Mauroy, o ex-primeiro-ministro (1981-1984) e prefeito da cidade (1973-2001), seguido pelo trem Eurostar em 1994, fazem um "cruzamento europeu", ${ }^{9}$ retomando a expressão comumente usada entre Paris, Bruxelas e Londres. A obtenção do título de Capital Europeia da Cultura, em 2004, amplia a visibilidade da capital de Flandres e constitui outro 
símbolo frequentemente invocado para caracterizar a renovação de Lille. Os dados demográficos ilustram esta dinâmica. Em 1968 a cidade possuía 238.554 habitantes, baixando para apenas 212.597, em 1999, antes de aumentar novamente para 222.784, em 2008, até a aglomeração de Lille (Lille Métropole Communauté Urbaine $\left.-\mathrm{LMCU}^{10}\right)$, neste último ano, atingir seus 1.105 .080 habitantes. ${ }^{11}$

Para caracterizar resumidamente a dinâmica urbana de Wazemmes, convém notar que Lille é uma das cidades francesas que conheceram um grande aumento dos preços dos terrenos. A situação do bairro, a tendência pouco acentuada de aumento dos preços somente nas áreas mais populares, como a Cidade Velha [Vieux-Lille], as tornam uma ótima opção para interessados em locação ou ascensão à casa própria. Para alguns esta é uma possibilidade rara de adquirir um imóvel não muito longe do centro da cidade, e às vezes uma oportunidade para uma primeira etapa com o espírito de revender sem prejuízos, com o ganho de permitir a compra de uma acomodação mais espaçosa, ou melhor localizada, segundo os projetos. Perto do centro da cidade, o bairro de Wazemmes tinha 20.548 habitantes em 1990, 22,42\% deles com idade inferior a 19. Em 2004 eram 25.362 habitantes, e 26.214, em 2008. O crescimento da população pode ser observado desde 1990: ele é de 7,75\% entre 1999 e 2004, um dos mais altos da cidade, junto com a Cidade Velha, espaço também revalorizado. Para entender melhor esse fluxo é necessário sublinhar uma diminuição populacional nos anos 1960 e 1970, porém, antes disso, o bairro não parou de crescer desde 1858, ano da incorporação deste antigo vilarejo a Lille, para então ver um forte decrescimento da população em função das crises do têxtil e da industrial, nos anos 1970 e 1980, respectivamente. A análise por íris (unidade de base utilizada pelo INSEE ${ }^{12}$ - o distrito possui várias delas) mostra que a ocupação por classe social varia muito entre os que estão perto do centro e os que estão na periferia. Para a prefeitura do bairro, essas mudanças nos últimos anos são um sucesso ("Esse bairro antigo e popular soube operar uma profunda transformação”). Eles salientam que o interesse por Wazemmes excedeu em muito os limites do bairro e da cidade - as pessoas vêm de longe para o mercado de domingo (40 mil visitantes a cada domingo de manhã), bem como para a Rua Gambetta, que recebe diariamente numerosos visitantes sobre seus 1.200 metros de comércio linear. ${ }^{13} \mathrm{O}$ cosmopolitismo valorizado do bairro é difícil de entender, uma vez que visa destacar tanto a atratividade do mercado, como o comércio étnico ou a copresença de populações francesas e estrangeiras. As últimas são mais presentes nas Zonas Urbanas Sensíveis (ZUS), onde há 11,3\% de estrangeiros (7,9\% em Lille e $6,2 \%$ na comunidade urbana $\left.{ }^{14}\right)$, dos quais os norte-africanos são os mais numerosos, seguidos pelos asiáticos.

Esse deslocamento demográfico e essa distribuição espacial diferenciada dos grupos sociais são indicadores de gentrificação. Esta surge de uma 
dinâmica de valorização através do registro discursivo e pelas mudanças morfológicas do bairro. Podemos também dizer que é um embelezamento que resulta e produz efeitos sobre a população assim que essas transformações discursivas e físicas modificam o aspecto físico, a atratividade e a lógica imobiliária. Na verdade, ao invés de se limitar ao termo de gentrificação que aponta uma tomada de espaço pelas classes médias e um "emburguesamento" do local - o que seria tão difícil de identificar como de definir -, o termo embelezamento combina estetização da cidade e usos políticos da cultura em geral. No entanto, a questão é ambígua o suficiente para deixar questões abertas: trata-se de um investimento de fachada, simplesmente um processo de estetização das últimas décadas? Falta ainda, obviamente, entender como apreender tal processo, a sua emergência, a legitimação que o acompanha pelos atores ${ }^{15}$ e cidadãos, e como o investigador dele se apropria para estudo. Ele designa, aqui, tanto as operações concretas que impulsionam ou sustentam o Estado e as coletividades territoriais (Cidade de Lille, Comunidade Urbana, o Departamento do Norte e a Região Nord-Pas-de-Calais) para melhorar os aspectos físicos (edifícios, planejamento do espaço) e promover atividades artísticas e culturais, como a apropriação pelos usuários através de suas apreciações e comentários. O embelezamento discursivo, como é abordado aqui, resulta, assim, da atenção às intervenções feitas por vários atores, sem hierarquizar aqueles destacados pelos operadores institucionais ou associativos e os testemunhos dos habitantes. O embelezamento ou estetização dos espaços urbanos é, portanto, sujeito a duas considerações: pelos discursos dos atores públicos e pelos processos de apropriação do espaço, especialmente durante a implantação de eventos culturais e festivos. No entanto, é difícil situar a significação da arte, da cultura ou da arquitetura (da forma como ela se manifesta na modificação da utilização dos courées ${ }^{16}$, pelo design da Maison Folie Wazemmes ${ }^{17}$ ) na transição para o período pós-industrial, no nível de um bairro, quanto mais de uma cidade. Trata-se da arte assim como é definida por instituições culturais (museus, teatro)? Ou devemos compreender a palavra cultura como abrangendo todas as atividades que são referenciadas a ela (desde aquelas propostas pelos equipamentos socioculturais até as manifestações mais midiatizadas)? Para melhor situar esta dinâmica, sem dúvida vale a pena recordar que o uso da cultura como um suporte da ação pública não se restringe aos centros urbanos e desenvolvidos nos subúrbios franceses. Mobilizada com a meta de empoderamento e de valorização das capacidades das populações, ou para promover esses espaços esteticamente, a cultura é, neste contexto, legitimada pela afirmação de sua vocação social ou denunciada como instrumentalização. ${ }^{18}$ É assim que, em relação à política da cidade, nasceu, em 1989, o Subúrbios 89 [Banlieues 89], seguidos dos Bairros de Luz [Quartiers Lumières], em 1991, as operações de Iluminação Pública e Luzes Urbanas [Opération d'Eclairage Public et Lumières Urbaines], em 1995, e 
de Paisagem e Integração Urbana [Opérations de Paysage et Intégration Urbaine], em 1996. Em relação à cadeia europeia, a cidade de Lille, assim como muitas outras, aumenta o investimento em cultura para fortalecer a sua influência e sua atratividade enquanto aglomeração fronteiriça. A ação cultural em Lille necessitou, no longo prazo, de uma combinação do que é considerado uma continuidade da cultura popular de um passado agora parcialmente valorizado (pelas associações entre as pessoas e por uma vida social supostamente mais dinâmica hoje em dia, por exemplo) e de intervenções mais ou menos diretamente relacionadas à arte contemporânea. A propósito, as mudanças físicas ocorrem ou são apresentadas como uma combinação entre apropriação contemporânea (a Maison Folie Wazemmes, os lofts ${ }^{19}$ ) e renovações ou reabilitações para refazer as fachadas. As inovações arquitetônicas parecem ser bem aceitas pela população, não havendo negação manifesta entre os entrevistados. Este processo é acompanhado por uma valorização da dimensão "festiva" do bairro, através dos festivais e das festas populares apoiadas institucionalmente (festa do acordeão com "Wazemmes a Sanfona 2012" [Wazemmes l'Accordéon 2012], festa da sopa com o " $12^{\circ}$ Festival da Concha de Ouro" [12 ${ }^{\text {ème }}$ Festival de La Louche d'Or], em 2012). Mesmo que alguns episódios sejam lembrados, como a tentativa frustrada de transformar Halles em complexo de cinema, que suscitou uma forte oposição para preservar esse equipamento, não encontramos, hoje, traços de oposição radical. Como explicar que esta vontade de criar combinando passado e presente não seja contestada pelos habitantes e organizações? Em tal contexto de relativa mudança da população e de etiquetagem da área pela cultura, as rejeições, analisadas por Nathalie Heinich (2009), são menos observadas. As produções estéticas contemporâneas ou as que aparentam como tal parecem suscitar, por vezes, a indiferença, sendo seguida, sem dúvida, pela banalização, por exemplo, em relação a certas formas arquitetônicas como aquelas da Maison Folie Wazemmes, ou, mais amplamente, aquelas da arte contemporânea. Presumivelmente, há uma maior aceitação de um objeto dotado de diversos significados e sentidos, os quais estão obscuros aos olhos do observador - estar em um lugar sem querer necessariamente compreender os objetos, eventualmente artísticos, cuja função nos foge e sem se sentir agredido por não entendê-los. Levemos em conta que a indiferença não exclui as relações de dominação, como propôs Pierre Bourdieu (1979), mas a análise completa, o que requer mais atenção aos aspectos cognitivos dos usuários, indica outro contexto de recepção. 


\section{ALTERIDADE RESSIGNIFICADA?}

Além da validade ou não das suposições relativas aos cruzamentos harmoniosos neste contexto, é levantada novamente a questão dos fundamentos da urbanidade: a alteridade. A cidade é, para muitos sociólogos, desde Weber aos da Escola de Chicago (Grafmeyer \& Joseph, 1984), um espaço de redefinição de lugares e até mesmo, segundo o primeiro, de confraternização e, segundo os últimos, de encontro com o desconhecido. O princípio da diferenciação - na base de todo o espaço social - é considerado uma evidência: todo cidadão é forasteiro, ${ }^{20} \mathrm{e}$, ao mesmo tempo, reconhece-se entre alguns mais do que entre outros. Para ser admissível e encontrar a sua tradução por meio de pesquisa empírica, esse amplo questionamento pode ser somente referenciado a uma sequência espaço-tempo, sem a pretensão de incluir todos os fatores envolvidos que não podem ser analisados para este artigo, e que constituem, por assim dizer, pontos cegos. Assim, a dinâmica urbana sobre o registro dos loteamentos, da fiscalização e da evolução dos preços não se dá, obviamente, sem consequências. Esses elementos condicionam as escolhas. Por que, por exemplo, a classe trabalhadora evita Wazemmes como primeira escolha na sua busca por habitações nesse momento, e por que ela se torna viável para outra classe? A percepção de bairros possíveis ou desejáveis, a escala de avaliação que os candidatos fazem para uma habitação afeta a sua escolha e, sem dúvida alguma, sua primeira experiência de proprietários ou de inquilinos. Essa dimensão socioeconômica não será objeto de investigação. Nós também não lidaremos com o complexo sistema de organismos que funcionam como intermediários (agências imobiliárias, locadores sociais, habitações por aluguel moderado). Apesar desses limites, o espaço urbano abordado pelo prisma do encontro se oferece como um bom indicador da construção social da alteridade. Nesta perspectiva, os cruzamentos, as passarelas, os estacionamentos, se tornam cadeias onde acontece a definição de si e as apropriações de lugares, e todo o tipo de interações para limitar ou até canalizar o incerto. Os relacionamentos que surgem na vizinhança ou nos espaços são indicadores dessa dinâmica e dos processos pelos quais a familiarização com lugares ou com pessoas se nutre das transações capazes de reduzir os medos inerentes ao espaço urbano. Retomando Isaac Joseph, ocorrem nos encontros "dois limites, ambos muito aterrorizantes: o terror da identificação - o espaço público é um espaço de traidores e tradutores - e o terror da invasão - o espaço público é um espaço de reservas e de partições" (Joseph, 1984: 14-15). No entanto, devido a uma série de gestos, de convenções e de instituições, a estranheza é canalizada para se tornar ausente ou ao menos banalizada. Sem retomar o questionamento sobre os fundamentos da alteridade, só podemos nos perguntar sobre a relevância das estratificações feitas para capturar a realidade social, uma vez que se supõe 
que ela seja móvel. Essas estratificações emergem, por um lado, de um exercício epistemológico e, por outro, de uma categorização prática feita pelos cidadãos em suas vidas cotidianas. Este é o caso das palavras "étnico" ou "cultural", muitas vezes usadas para distinguir um grupo majoritário de uma ou mais minorias, tidos como diferentes. É também questão de etnicidade, entendida como um processo de situação - entre "olhar" e "discurso", de posição e de oposição - e como uma relação herdeira, na França de 2010, de assimétricas referências do período colonial. É mais apropriado falar de etnicização para sublinhar que as linhas divisórias operadas pelos indivíduos resultam de socialização e de publicitação. As distâncias e as proximidades são percebidas e ativadas pelas pessoas segundo a aprendizagem social em meios condicionados pelo debate no espaço público e a estrutura social em diferentes períodos vividos. Assim, as pessoas que passaram sua infância no contexto colonial francês dos anos 1950 e 1960 não percebem Wazemmes da mesma forma que aqueles que foram educados nos bairros populares nos anos 1980 e têm sido mais ou menos receptivos às discussões sobre os subúrbios. Abordar a questão da alteridade permite retomar um conjunto de questões formuladas em termos de imigração, cultura, interculturalidade e multiculturalismo, sem, contudo, suscitar reservas. O receio, na verdade, é o de retomar as segregações instituídas, sobretudo pela referência ao Estado-nação e à ou às culturas supostamente inerentes a ele. A abordagem pela socialização da alteridade retoma essas questões e elimina as supostas fixações associadas tanto à tradição como à cultura. Trata-se da contextualização de dois tempos, necessariamente arbitrários em suas delimitações, aquele de aprender sobre o mundo e o de testar o mundo. Obviamente, esta clivagem é parcialmente artificial, na medida em que nenhum dos dois elementos é exclusivo: a aprendizagem é também um teste. Mas a idade e o status limitam as margens de manobra que podemos supor serem maiores na idade dita adulta em nossas sociedades.

É a utilização dos lugares, a residência, as relações de vizinhança, a frequentação de praças, de lojas, o uso de transportes públicos, que indicam como são construídas socialmente a ancoragem e a apropriação ao longo do tempo. Sobre a ancoragem, é necessário situar os indivíduos em suas primeiras relações com a cidade: habitantes do meio urbano ou rural durante a infância, o qual há que se entender como era sua percepção durante sua infância e como ela é hoje. Quanto à apropriação, ela corresponde às práticas contemporâneas através das quais o indivíduo estabelece uma familiaridade com alguns mais do que com outros. Consequentemente, o bairro não é apreendido por todos da mesma maneira. Pesquisas mostram que, se a grande maioria dos habitantes usa o nome Wazemmes, outros o designam pelo nome da rua (Gambetta, por exemplo), ou ainda a estação de metrô mais próxima. As fronteiras sociológicas e espaciais a que os usuários se referem 
são múltiplas, como as divisões administrativas para agir sobre o transporte e a segurança, entre outros exemplos, sem mencionar aquelas do INSEE ou da política da cidade com a ZUS que corresponde a 5\% do território de Lille e abriga 10.416 habitantes (Vignier, 2012).

Ao longo de meses, dependendo dos dias, e em horas diferentes, a observação revelou uma variação de situações. Estas se dão em copresença de mulheres e homens, de diferentes idades e aparentemente de diversas origens que, evidentemente, envolvem todos os participantes e não poderiam ser reduzidas às figuras estrangeiras. De fato, há uma enorme variedade de transeuntes, se observarmos o vestuário e as línguas estrangeiras faladas. É difícil caracterizar essas alteridades e esses cruzamentos definidos pelos entrevistados, desde o próximo ao distante, parafraseando o título de Bastide, a partir das aparências e dos comportamentos visíveis entre as populações "jovens", os quais chamamos de imigrantes, até os migrantes mais típicos da África do Norte ou da Ásia, entre aqueles que perambulam em família e aqueles que bebem nas varandas dos bares, às vezes em estado próximo à embriaguez. Nenhum destes está presente, eles não se cruzam nem no mesmo espaço, nem no mesmo tempo. Os cruzamentos tampouco implicam o mesmo nível de compromisso, desde a passagem para a estação de metrô Gambetta, onde se reúnem grupos de jovens muitas vezes alcoolizados, barulhentos, acompanhados sempre de muitos cães e suscitando mais ou menos desconforto, ao intercâmbio de compradores e vendedores, na manhã de domingo, quando os cafés estão lotados e a praça da feira esta abarrotada de gente. $\mathrm{Na}$ feira, localizada na Praça la Nouvelle Aventure, no coração do bairro, assim como nas proximidades, instalações exóticas expõem estandes de roupas, de tecidos, de utensílios de todos os tipos, de frutas e de legumes. O centro da feira do Halles - um belo edifício construído na segunda metade do século XIX conforme modelos de Paris - é repartido entre 22 comerciantes, oferecendo peixe, carnes, produtos locais, asiáticos, orgânicos, comércio equitativo. ${ }^{21}$ Externamente, em toda a extensão ao redor do Halles, encontramos aqueles estandes com os produtos exóticos e comida asiática e norte-africana. Fora dos dias de mercado (domingos, terças e quintas-feiras), certos períodos, como o Ramadã ${ }^{22}$, ficam mais movimentados, sobretudo nas duas ruas adjacente a ele, rue des Sarrasins e rue Jules Guesde, com barracas de doces recheados, bolos e outros produtos mediterrânicos. Esta última rua, com seus comércios étnicos ou antiquados (como a espaçosa boutique de bolas de lã de tricô) e seus pequenos grupos de homens, aparentemente estrangeiros, e, talvez, em situação precária ou clandestina, possui um status particular para alguns habitantes. Ela é vista como rua de tráfico, acima de tudo de droga, e uma das menos seguras.

Muitos entrevistados enfatizaram a presença do lazer a toda hora. Muitas mulheres, especialmente aquelas que vivem sozinhas, disseram não se 
importar com a hora de voltar para casa, à noite. A solidão é compensada, segundo eles mesmos, com oferta de atividades culturais ou saídas perto do local de residência ou no centro da cidade. Os jovens casais que moram juntos também insistiram neste aspecto. É preciso ressaltar, no entanto, a existência de reservas e preocupações também relatadas. A primeira envolve certas áreas do bairro, como essa rua que uma habitante (50 anos, professora) relatou estar sendo completamente tomada por árabes do Magrebe. ${ }^{23}$ Esta observação é esclarecedora por diversas razões. Ela é um indício da relativa centralidade desta rua para alguns migrantes ou pessoas relacionadas, de alguma forma, com os países do Magrebe. O grande número de lojas que oferecem preços aparentemente atraentes em ligações para esta região (entre outras) atesta esse fato, segundo algumas opiniões. Nenhuma etnicização deste tipo é feita em relação aos asiáticos, inseridos principalmente em uma função comercial a qual a presença não suscita guerras de comentários. Mas em relação à história social de diversos entrevistados que tenham vivido em bairros populares caracterizados por uma forte presença de imigrantes, esta observação e ainda o desconforto relatado pela entrevistada citada, mostram uma dupla mudança. Primeiro, a presença dessas lojas e outros comércios chamados étnicos parece mais evidente aos seus olhos. Em segundo lugar, em contraste com o que ela relata ter vivido na infância e na adolescência, em certos momentos ela não se sente mais "no seu lugar." Ela conta, para ilustrar seu relato, um episódio no qual ela sentiu necessidade de voltar para casa para trocar de roupas depois de sentir olhares de desaprovação. O relato de outra mulher um pouco mais velha (aposentada) conforma a ideia de uma ambivalência que não encontra sempre as palavras para exprimir a complexidade das relações com aqueles que supostamente se referem a outra cultura. Esta mulher relata o que lhe parece um paradoxo relacional com um comerciante: ela tem o hábito de comprar frequentemente em sua loja, lugar onde o comerciante a cumprimenta e conversa longa e cordialmente com ela, porém ele a ignora quando se cruzam na rua. Depois de muitas tentativas, a mulher se rende a esses cruzamentos silenciosos, mesmo que eles a deixem perplexa e incomodada. Em relação a esse registro de cruzamentos, que os indivíduos qualificam como culturais ou interculturais, é interessante observar que outros bairros, como Belleville ou Ménilmontant, em Paris, experimentam processos semelhantes, assim como os restaurantes que oferecem refeição de regiões rurais do Magrebe, ou pratos à base de carne fria [charcuterie] francesa e não halal. ${ }^{24}$ É verdade que em certos estabelecimentos a experiência é de curta duração e não está claro se a implantação recente de livrarias de literatura Islã condiciona essa mudança ou não. De qualquer forma, as copresenças, raras ou improváveis na década de 1970, entre imigrantes "solteiros" 25 e jovens mulheres, por exemplo, se multiplicaram. Muitos sinais atestam essas mudanças entre dois períodos. Os sinais mais visíveis 
são as varandas dos bares e cafés com uma clientela tanto francesa como estrangeira, onde homens e mulheres bebem um chá de hortelã ou um nass-nass (literalmente "meio-a-meio" em árabe, significando café com leite). Essas bebidas são menos exóticas para estes clientes, são consumidas mais regularmente e sugerem que esses locais de possíveis encontros hoje revelam uma percepção diferente daquilo que foi estranho, exótico ou atraente, apesar de não familiar. Paralelamente, o comportamento público de certos imigrantes ou de seus filhos aparece de forma mais aberta, por exemplo, no plano religioso. Em Wazemmes, alguns restaurantes oferecem refeições gratuitas para quebrar o jejum em certos dias do Ramadã (em 2010).

Outros temores e rejeições podem ser observados de forma mais clara. Algumas ruas, apesar de serem próximas da Praça do Mercado (área central do bairro) e de seu frequente movimento, suscitam pelo menos uma apreensão durante a noite. As apreensões concernem principalmente ao consumo excessivo de álcool, outra dimensão da convivência ou outro aspecto que mostra a ambivalência da festa, atraente e repulsiva ao mesmo tempo. Os comerciantes, quando falam sobre isso, se referem a um comportamento e a uma embriaguês perigosos, próprios de uma população difícil de identificar, a não ser pelo termo genérico de marginais. Algumas atitudes expressam uma valorização permeada por medo. Por exemplo, uma nova residente (professora, 27 anos) expressa uma cautela nos primeiros meses de sua instalação em 2011, o que não diminui sua apreciação positiva por sua habitação e seu meio ambiente. Seu companheiro (engenheiro, 27 anos) é mais relutante em relação aos cruzamentos. Outro jovem adulto (desempregado, 28 anos) e sua esposa (funcionária, 26 anos), instalados há mais tempo, contrariamente, expressam sua satisfação e seu prazer de viver ali, referenciando o bairro pelas oportunidades de festas que ele oferece. Outros, como esse comerciante (55 anos) e sua esposa (área de administração, 52 anos) destacam a continuidade entre a Cidade Velha, bairro então popular durante a sua infância, e Wazemmes, onde experimentaram recentemente vários atos de vandalismo em seu carro. Uma nova residente vinda de uma pequena cidade sem Zona de Urbanização Prioritária (ZUP) (professora, 27 anos) disse também que a "passagem" por Wazemmes não lhe incomoda. Nos dois últimos casos, como em outros mencionados acima, o paralelismo entre a situação na infância e a atual sugere contextos bem diferentes. Para os mais velhos, esta comparação se embasa também em uma avaliação e uma comparação entre dois períodos de tempo, entre os anos de 1970 e 2012, o que nos faz questionar a relevância das categorias usadas ("popular", "classe média”, "ZUP” ou "periferia") e sua ressonância ou recepção em cada período. Os entrevistados enunciam subjetivamente essa comparação, isto é, pela sua história e pela dupla contextualização entre seu passado e presente. Estariam os "bairros" da década de 1970, aos olhos deles, mais "distantes" destes de 2010? Esta é a dificuldade 
de conceituar essas diferenciações práticas e sua evolução ao longo do tempo.

Além das ruas mencionadas acima, um conjunto de residências da década de 1970, tendo recebido uma reabilitação na década de 1990, também suscitam reações ambivalentes semelhantes àquelas dos bairros ditos sensíveis (Magnier, 2012). A intensa atenção dos agentes públicos com questões de segurança, bem como os relatos dos jovens adultos desse conjunto ou das cercanias, explicitam a difícil estruturação intergeracional da vida social de lugares assim. Com o risco de serem excessivamente esquematizadas, essas dificuldades tornam mais visíveis os problemas sociais geralmente associados às ZUPs. Essas relações são provavelmente mais variadas conforme as idades e os percursos residenciais dos locatários (pais mais preocupados do que casais sem filhos, por exemplo). Situado no interior de Wazemmes, esse conjunto habitacional constitui um dos polos da dinâmica do bairro, local de muita tensão, segundo os entrevistados, por oposição à parte do bairro mais próxima ao centro da cidade e quase confundida com ele. Essas diferenças de apreciação se reencontram na distribuição das categorias sociais e nas taxas de desemprego (ver Vignier, 2012). As subpartes do bairro, de fato, não acolhem os mesmos tipos de população. Assim, Brigode abriga uma grande proporção de executivos (mais de $20 \%$ ) e uma taxa baixa de desemprego (6\%), enquanto Sarrazins-Magenta, parte que concentra a residência social, conta com $23 \%$ de desempregados e uma alta proporção de operários. Essa cartografia não é muito distante daquela apresentada pelos habitantes mais engajados na vida social do bairro. Como essa antiga comerciante (aposentada, 71 anos) que lidera uma associação voltada para história do bairro e que distingue as partes "tranquilas" daquelas cuja reabilitação está, aos seus olhos, inacabada. Isso se reflete parcialmente na frequentação de um estabelecimento como La Maison Folie Wazemmes. A presença dos habitantes do bairro vai de $16 \%$ (para um espetáculo de dança hip-hop) ate $24 \%$ (para um espetáculo voltado para crianças) (Vignier, 2012). ${ }^{26}$ Trata-se de um indicador que convém utilizar com precaução quando não se possui dados globais na escala do bairro, e quando as categorias sociais desses públicos não são conhecidas. Quanto a esse equipamento cultural, uma parte dos comerciantes é desfavorável porque ele atrai, nas manifestações como a festa do acordeão, muitos clientes que consomem bebidas e comidas no lugar, e não em casa. 


\section{CONCLUSÃo}

Wazemmes tem um status ambivalente que, aparentemente, não denigre a sua imagem. Por um lado, ele se beneficia de uma área delimitada por critérios sociais do status de Zona Urbana Sensível (ZUS), e como tal recebe ajudas específicas, mas sem ser, contudo, estigmatizado como subúrbio. Por outro lado, ele se apresenta como um espaço cosmopolita harmonioso. À luz das entrevistas, ele fornece um quadro suficientemente atraente e reconfortante para que cada um se aproprie dos espaços segundo suas expectativas, enquanto exclui ou limita passagens em lugares menos apreciados. A multiplicação das atividades culturais, em concordância com a requalificação dos edifícios, renovação das habitações etc., são operações concretas participando da transformação que se queria medir pela recomposição da relação presente/passado (o que não pode ser apagado pela demolição). As mudanças físicas são geralmente valorizadas ou consideradas como melhorias pelos entrevistados, sendo raramente vinculadas a críticas sobre a vida social no bairro. Aos poucos, certas pessoas descobrem algumas desvantagens (barulho, roubo, tráfico) e vivenciam desapontamento. Mas são principalmente as relações de gêneros ou de gerações que indicam as dificuldades de relacionamento, se queixam tanto do desconforto suscitado pelos "jovens", quanto pelo "olhar" de alguns homens, bem como pela apreensão por uma lógica de difusão de normas culturais e religiosas para além das ruas chamadas "magrebenizadas" ["maghrébinisées”]. A declaração desses problemas é um exercício delicado, especialmente para aqueles que temem não encontrar as palavras para não reforçar os estereótipos ou parecer racista. Para estender e ampliar a análise dessas posições e da lógica relacional que as sustentam, seria apropriado refinar a análise do município como um todo, compreendido como um espaço dividido por "fronteiras" físicas e simbólicas. Seria interessante, nessa perspectiva, elaborar um mapa desses subespaços e combinar isso com a análise da distribuição das dinâmicas sociais que são próprias a eles, abordadas a partir da perspectiva da alteridade e das práticas culturais. Aprofundando a análise da construção social e da administração pública da alteridade, veríamos como cada um forja, na sua vizinhança e no resto do bairro, sua familiaridade, suas proximidades e distâncias, semelhante a como fizeram, em 1970, Jean-Claude Lemaire e Madeleine Chamboredon (1970) para os primeiros grandes conjuntos. Diferentemente dos resultados dos dois sociólogos, que sublinharam que a proximidade espacial não é suficiente para absolver as distâncias sociais, as pessoas, pelo contrário, se esforçaram em lembrar que aparece em Wazemmes uma sutil apreciação dos cruzamentos. Seria instrutivo tentar averiguar mais sobre os modos e graus de implicação para melhor entender a redefinição da alteridade e a dinâmica social do bairro. 
Abdelhafid Hammouche é sociólogo, professor da Universidade de Lille 1, diretor do Centro de Estudos e Pesquisas Sociológicas e Econômicas de Lille (Centre Lillois d'Études et de Recherches Sociologiques et Economiques UMR 8019 - CLERSÉ-CNRS); é também responsável pelo Programa de Mestrado em Sociologia e Etnologia (Parcours Master Sociologie et Ethnologie) e diretor do Mestrado em Sociologia e Antropologia de Questões Urbanas do Instituto de Sociologia e Etnologia de Lille 1. É membro da redação da Hommes \& Migrations. Pesquisa as dinâmicas sociais e a ação pública em áreas urbanas em perspectiva comparada, na França, no Brasil e no Japão. Publicou Politique de la ville et autorité d'intervention. Contribution à la sociologie des dispositifs d'action publique (2012). 


\section{NOTAS}

1 Max Weber fala da cidade antiga e medieval como uma "associação fraterna". Nesta perspectiva, a cidade está em constante construção, ela está sempre em processo de criação, entre estranhos, entre estrangeiros, considerando que só há estrangeiros; ou seja, não somente os imigrantes, mas todos os cidadãos são considerados sob um ângulo de alteridade mais ou menos morta. A confraternização, como definida por Max Weber, é o processo de estabelecer uma ligação através de uma "base" comum, através de um "alfabeto" compartilhado. Esta abordagem levanta questões sobre as incongruências parcialmente contidas nas novas relações. Ver Hammouche (2007).

2 Em Lille, outros bairros têm experimentado processos muito semelhantes ou às vezes menos acentuados que em Moulins. Ver a comparação de Sonia Vidal (s/d), apresentação oral em 16 de janeiro de 2012, na Maison Folie Wazemmes, em Lille; e também Ana Maria Barbosa Campelo de Melo (2011).

3 A ação pública implica, como em todo o território nacional francês, diversas administrações e serviços do estado. O bairro se beneficia de dispositivos suplementares específicos (financeiros e equipes para coordenar intervenções) para a parcela categorizada como Zona Urbana Sensível (ZUS) no quadro de Contrato Urbano de Coesão Social (CUCS). As ZUS são áreas urbanas selecionadas e delimitadas segundo critérios sociais como taxa de desemprego. O CUCS e as ZUS são instrumentos da política da cidade. Isto não se restringe a uma cidade em particular, mas é constituído em nível nacional para organizar todas as intervenções governamentais nas zonas pobres das cidades, quando acolhem populações que vivem em situações sociais difíceis ou quando, de forma mais ampla, as áreas são classificadas como locais sensíveis ou relegados. Múltiplas intervenções são agrupadas convenientemente sob o título de políticas da cidade, e o termo subúrbio*é, por vezes, confundido com Zona de Urbanização Prioritária (ZUP). Definido pelo perímetro e modo de ação, a política da cidade foi implantada pela primeira vez almejando agir sobre o habitat e o acompanhamento social, antes de ver surgir uma proliferação de atividades culturais e artísti- 
cas. Para aprofundamento sobre esta política, ver Hammouche (2012).

* Banlieue, lugar de baixa renda, habitado por imigrantes, termo com conotação depreciativa. O termo subúrbio esta sendo empregado aqui mais pelo seu caráter social que pelo geográfico, segundo a designação do senso comum - apesar de esta se opor ao sentido oficial e como é empregado pelo urbanismo, isto é, espaço que cerca uma cidade [N.T.].

4 A palavra sensível esta ligada à terminologia oficial da Política da Cidade. Ela indica a espacialização dos problemas sociais, sem, contudo, gerar controvérsia. A crítica mais amplamente enunciada é esta: como pensar esses limites em termos de área sensível (ou favelas no Brasil, por exemplo) e ouvir designações contemporâneas de ação em busca de legitimidade de vários atores? Devemos dizer bairro "gentrificado", espaços urbanos reconsiderados, para falar dessas "partes" da cidade sem tomar as denominações oficiais de bairros sensíveis, reclassificados etc.? Ou devemos enfatizar a solidariedade com as partes da cidade diferentemente dotadas de população, gerando recursos para problematizar a cidade como um todo?Para a noção de bairro enquanto uma categoria de ação pública, ver o trabalho de Sylvie Tissot (2007).

5 Veja a crítica desta abordagem por Alain Bourdin (2005).

6 A pesquisa que realizei no bairro de Wazemmes começou em fevereiro de 2011. Ela necessitou de observações regulares desde essa data e de rastreamento documental para um esboço da história da região e de seus usos atuais. Vários habitantes foram contatados, tendo em vista a composição das famílias e suas histórias no bairro.Quatorze entrevistas semiestruturadas foram realizadas (julho de 2012). A pesquisa é também enriquecida por várias investigações que se dirigem na mesma direção: a de Sonia Vidal, já citada; a de Mathilde Vignier (2012); a de Jeoffrey Magnier (2012). Esta investigação contou com um recurso de pesquisa desenvolvido de uma abordagem comparativa internacional, para a evolução de tais vizinhanças que coordeno, envolvendo Kadma Marques (Universidade Estadual do Ceará, Brasil, para o bairro de Iracema, Fortaleza), Shintaro Namioka (Universidade Meiji 
Gakuin, para o bairro de Kotobuki, na cidade de Yokohama, no Japão), Sonia Vidal (Universidade de Lille 1, França, para os bairros de Wazemmes e Mills).

7 Do original étranger. Além de estrangeiro, se traduz por estranho, desconhecido, não familiar [N.T.].

8 Na França o veículo é popularmente designado por TGV, sigla de train à grande vitesse [N.T.].

9 Carrefour européen [N.T.].

10 Estrutura de gerenciamento de coletivos regionais franceses [N.T.].

11 INSEE. Disponível em: <http://www.insee.fr/fr/regions/ nord-pas-de-calais/default.asp?page =themes $/$ tableau_de bord/TB02lmcu.htm>. Acesso em 9 ago. 2012.

12 Instituto Nacional de Estatísticas e Estudos Econômicos francês.

13 Disponível em: <http://www.mairie-lille.fr/fr/Votre_Mairie/Mairies_de_quartiers/Wazemmes>. Acesso em 31 jul. 2012.

14 Disponível em: <http://www.insee.fr/fr/ppp/bases-de-do-nnees/donnees-detaillees/duicq/pdf/ftd/ftd_z_3104140. pdf>. Acesso em 31 jul. 2012.

15 Por conveniência o termo ator será reservado àqueles que participam da ação pública.

16 Datando do século XIX e parte do século XX, o courée é uma coleção de pequenas casas de um andar, semelhantes entre si, uma de frente para a outra ao longo de uma rua pequena com acesso através de uma estreita passagem.

17 Equipamento cultural em Lille, inaugurado em 2004, provido de salas de exposição e espetáculos, espaços residenciais, de trabalho e de criações. Trata-se de um edifício modernizado, onde havia originalmente uma antiga usina [N.T.].

$18 \mathrm{O}$ autor Henri-Pierre Jeudy, por exemplo, denunciou a instrumentalização da cultura para fins sociais e culturais ("Quando se supõe que a mola do desenvolvimento cultural deva vir dos excluídos, tudo o que estes têm a valer é o seu direito de desintegração. Sua violência é um es petáculo! A emergência da diferença é apenas um sintoma da integração. E a arte em si assume uma missão social. 
Vindo auxiliar o trabalho social, os artistas parecem finalmente cumprir o seu papel na cidade uma vez que estão lá para realizar a harmonia do pluralismo cultural em áreas urbanas desgastadas. Toda a criação corre o risco de se prender à armadilha das razões e objetivos socioculturais que lhe conferem um sentido contra o qual ela não pode se opor. Os gestores da integração já foram à procura dessas formas nascentes de criação espontânea para operar a metamorfose da violência na estética social") (Jeudy, 1999: 24-25).

19 O loft é um armazém, ou um local profissional, transformado em um lugar residencial ou ateliê de artistas.

20 Do original étranger, além de estrangeiro, se traduz por estranho, desconhecido, não familiar [N.T.].

21 Disponível em: <http://www.halles-wazemmes.com/historique.html>. Acesso em 1 ago. 2012.

22 De 20 de julho a 18 de agosto de 2012. Este período de jejum referente aos muçulmanos praticantes é de 30 dias, começando a cada ano, de acordo com o calendário lunar, dez dias antes do início do mesmo período do ano anterior. Jejuar é abster-se de comer, beber, de qualquer relação sexual desde o amanhecer até pôr do Sol. É particularmente difícil no verão. Nas últimas décadas, quebrar o jejum à noite tem cada vez mais ganhado um aspecto festivo. O bairro de Wazemmes, como o de Belleville, em Paris, e outros nas grandes cidades francesas, abrigam uma grande comunidade muçulmana e se tornam mais animados durante este período, com uma participação mais ou menos ativa de comerciantes.

23 Nas palavras da entrevistada, a rua estaria sendo maghrébinisée - ato de proliferação do Magrebe; Magrebe - conjunto de países de religião islã compondo a parte ocidental do mundo árabe [N.T.].

$24 \mathrm{O}$ alimento permitido no Islã de acordo com as regras escritas no Alcorão. Em árabe significa lícito [N.T.].

25 A expressão "solteiro geográfico" indica que o imigrante vive sozinho na França, enquanto sua esposa e, se for o caso, seus filhos, permanecem no país de origem.

26 Pesquisa realizada entre janeiro e julho de 2012. 


\section{REFERÊNCIAS BIBLIOGRÁFICAS}

Authier, Jean-Yves \& Bidou-Zachariasen, Catherine. (2008). Editorial. La question de la gentrification urbaine. Espaces et Sociétés, 1/132-133, p. 13-21.

Bassand, Michel; Kaufmann, Vincent \& Joye Dominique. (2007). Enjeux de la sociologie urbaine. Lausanne: Presses Polytechniques et Universitaires Romandes.

Bastide, Roger. (2000). Le prochain et le lointain. Paris: L'Harmattan.

Blanc, Maurice. (1988). Concertation, sociologie urbaine, citoyenneté. Les Annales de la Recherche Urbaine, 38, jun/jul, p. 104-112.

Bourdieu, Pierre. (1979). La distinction: critique sociale du jugement. Paris: Minuit.

Bourdin, Alain. (2005). La "creative class" existe-t-elle?. Reuue Urbanisme, 344, set/out. Disponível em <http://www. urbanisme.fr/issue/report.php? code $=344$ \# article238 $>$. Acesso em 27 abr. 2013.

Chamboredon, Jean-Claude \& Lemaire, Madeleine. (1970). Proximité spatiale et distance sociale. Les grands ensembles et leur peuplement. Revue Française de Sociologie, XI/1, p. 3-33. Elias, Norbert. (1991). La société des individus. Paris: Fayard. Florida, Richard. (2002). The rise of the creative class. And how it's transforming work, leisure, community and everyday life. Nova York: Basic Books.

Gaudin, Jean-Pierre. (1985). "La cité reconstituée”. Techniques de planification urbaine et légitimités politiques au début du 20e siècle. Revue Française de Science Politique, 35/1, p. 91-110.

Glass, Ruth. (1963). Introduction to London: Aspects of change. Londres: Center for Urban Studies.

Grafmeyer, Yves \& Joseph, Isaac (orgs.) (1984). L'école de Chicago, naissance de l'écologie urbaine. Paris: Aubier.

Hammouche, Abdelhafid. (2012). Politique de la ville et autorité d'intervention. Contribution à la sociologie des dispositifs d'action publique. Lille: Presses Universitaires du Septentrion. Hammouche, Abdelhafid. (2007). Les recompositions culturelles. Sociologie des dynamiques sociales en situation migratoire. Estrasburgo: PUS. 
Hammouche, Abdelhafid. (1994). Mariages et immigration: La famille Algérienne en France. Lyon: PUL.

Hannerz, Ulf. (1983). Explorer la ville. Paris: Minuit.

Heinich, Nathalie. (2009). L'art contemporain exposé aux rejets. Paris: Hachette Pluriel.

Jeudy, Henri-Pierre. (1999). Les usages sociaux de l'art. Paris: Circé.

Joseph, Isaac. (1984). Le passant considérable. Essai sur la dispersion de l'espace public. Paris: Librairie des Méridiens. Jourdan, Silvère. (2008). Richard Florida, Cities and the creative class. Méditerranée, 111 [online]. Disponível em < http://mediterranee.revues.org/2878>. Acesso em 20 abr. 2013.

Magnier, Jeoffrey. (2012). “C'qu'il est blême mon HLM” - Décomposition des modalités d'appropriation de l'espace: l'exemple de la cité résidentialisée Magenta-Fombelle dans le quartier de Wazemmes. Dissertação de Mestrado. Universidade de Lille 1.

Melo, Ana Maria Barbosa Campelo de. (2011). La planification stratégique et ses effets sur les métropoles. Analyse des expériences de Lille (France) et de Recife (Brésil). Tese de Doutorado. Universidade Paris 3.

Tissot, Sylvie. (2007). L'Etat et les quartiers. Genèse d'une catégorie de l'action publique. Paris: Seuil.

Vidal, Sonia. (s/d). Politique culturelle territorialisée et transformations des "paysages" métropolitains: analyse comparée de l'action des Maisons Folies dans deux quartiers populaires de Lille. Projeto de Doutorado em curso. Universidade de Lille 1.

Vignier, Mathilde. (2012). Approche sociologique de la Maison Folie de Wazemmes et ses publics. Dissertação de Mestrado. Universidade de Lille 1.

Weber, Max. (1982). La ville. Paris: Aubier. 
Palavras-chave

Cidade; Alteridade;

Gentrificação;

Relações de gênero;

Geração.

Keywords

City; Alterity;

Gentrification; Gender

relations; Generation.
VALORIZAÇÃO DE BAIRROS ANTIGOS E RESSIGNIFICAÇÃO DA ALTERIDADE: O EXEMPLO DE WAZEMMES EM LILLE

\section{Resumo}

Este artigo examina a dinâmica urbana em bairros submetidos à gentrificação, mais precisamente aquela de Wazemmes, bairro perto do centro da cidade de Lille, no Norte da França. Em Wazemmes ocorreram mudanças sensíveis nas últimas décadas. O bairro tornou-se um espaço cosmopolita, onde convive uma população de grande diversidade. Conta com uma ação pública em domínios variados, sobretudo nos registros social e cultural. De um espaço difamado em razão da delinquência, e do medo por causa da forte presença de imigrantes, é agora valorizado, tornando-se um lugar emblemático quanto à sua urbanidade e sua etnicidade.

\section{THE IMPROVEMENT OF OLD NEIGHBORHOODS} AND THE RESIGNIFICATION OF ALTERITY: THE CASE OF WAZEMMES IN LILLE

\section{Abstract}

This article examines the urban dynamics of neighborhoods undergoing gentrification, particularly the neighborhood of Wazemmes, located close to the center of Lille, in Northern France. Significant changes occurred in Wazemmes in the last decades. The neighborhood became a cosmopolitan space joining a population of great diversity. It was subjected to publicaction in a variety of domains, affecting mainly the social and cultural registers. Wazemmes changed from being an infamous space associated with delinquency and danger because of the strong presence of immigrants to an emblematic place now esteemed for its urban and ethnic features. 